\title{
Attitude of Parents towards Sex Education
}

\author{
Aarti N Nagpal ${ }^{1}$, Dr. Sr. Christine Fernandes ${ }^{2}$
}

\section{ABSTRACT}

The value of sex education for teenagers has been emphasized by social activists, psychologists and social scientists so that they may not become a victim of Sexually Transmitted Diseases such as HIV/AIDS, sexuality related complications and to eradicate social evils such as eve-teasing, sexual harassment and also to help the young people gain knowledge on the ability to protect themselves from sexual exploitation and threats. The purpose of this study is to measure the attitude of parents of teenagers aged 13-19 years towards sex education. Thirty parents of teenagers from the metropolitan city of Hyderabad were included in the sample. Purposive sampling method was used for this research. Attitude Scale towards Sex Education developed by Dr. Usha Mishra (2008) was used to measure the attitude of parents of teenagers. The results show that the parents of today's teenagers have a positive or a high attitude towards sex education thus supporting the hypothesis and contradicting the earlier studies. The mean difference between fathers and mothers is not noted to be very high and the t-ratio obtained is 0.448 which is not statistically significant. This shows that there is not much of gender variation in the attitude towards sex education. Since the present study contradicts the earlier studies, it comes out with a proposal stating that more studies could be established on a wider level to support the change in attitude of parents towards sex education over decades. Also, the government could make use of the change in parents' attitudes and come up with policies for involving formal Sex Education in the educational institutions.

Keywords: Attitude, Parents, Sex Education

Human sexual behavior in India has been influenced by different attitudes and opinions over time. India pioneered the use and application of sex education through art and literature although it has not been formally applied by the government in the academic curriculum of a majority of educational institutions and has also been objected by the parents of teenagers in the past. Sex education is a broad term used to describe education about human anatomy which includes a sex organ or any other body parts which are involved in sexual reproduction. It also seeks to impart basic education on sexual intercourse, reproductive health, emotional relations,

\footnotetext{
${ }^{1}$ Ph.D Scholar, University of Hyderabad

${ }^{2}$ Principal, St. Francis Degree College, Hyderabad

(C) 2015 I A Nagpal, C Fernandes; licensee IJIP. This is an Open Access Research distributed under the terms of the Creative Commons Attribution License (http://creativecommons.org/licenses/by/2.0), which permits unrestricted use, distribution, and reproduction in any Medium, provided the original work is properly cited.
} 
reproduction rights, use of contraceptives, menstruation, pregnancy and other aspects of human sexual behavior. Not only this, sex education also plays a vital role in spreading awareness on abortion and Sexually Transmitted Diseases. However, sex education may differ from state to state, country to country depending on the norms laid down by the society.

High school students and adolescents have a right to obtain information on various aspects of sex education at the right time, as sex education is more than just knowing about sexual intercourse. It is to be imparted in such a way that it helps youngsters to incorporate sex more meaningfully into the present and the future. It may either be imparted informally through books, magazines, media and websites or formally through sex education classes in schools and educational institutions. It has widely been accepted that some kind of planned sex education is necessary. Considering the Indian scenario, most of the schools offer no sex education since it remains to be a highly controversial issue especially with respect to the right age at which the children should receive such kind of information and also the methods in which such information is passed to them. Wilhelm Reich commented that sex education of his time was a work of deception, focusing on biology while concealing excitement-arousal, which is what a pubescent individual, is mostly interested in. He added that this emphasis obscures what he believed to be a basic psychological principle that all worries and difficulties originate from unsatisfied sexual impulses (Sophie Borland, 2007).

A study done by Libby (1970) on Parental Attitudes toward High School Sex Education Programs indicated that majority of parents approved sex education although, contradictions were noted. Parents wanted sex education to be taught in the context of God, marriage and parenthood. Oiekh (1981) blamed emotional rather than logical approaches to the evaluation of the need for teaching of sex education, for the controversy that has inundated the institutionalization of the program in most parts of the world. In a survey conducted by Hovell (1994) on Family Influences on Adolescents Sexual Behavior, revealed that conservative maternal attitudes about sex, delay the development of an individual or sexual behavior.

Another study done by Shetty.P, Kowli.S and Patil.V (1999) pointed out that the mothers were reluctant to talk about sex education to their daughters. Although, the mothers perceived that girls should talk only about menstruation and it is necessary for the girls to be aware of intercourse or other important aspects pertaining to sex education. The mothers found it embarrassing to discuss on such issues with their daughters. Dialard.C (2001) pointed out on a significant change of attitudes of parents towards sex education to their children. With the beginning of the $21^{\text {st }}$ century, the attitude of parents has shifted from negative to positive. Most parents $(65 \%)$ believe that sex education should be imparted on the grounds that it should encourage young people to use birth control and practice safe sex once they become sexually active.

A recent study by Mahajan.P and Sharma.N (2005) said that it is ironical that while sex plays an important role in India, parents, teachers and significant others hardly play any role in imparting proper information to the youngsters. There is a strong need to provide appropriate 
information to adolescents which is often opposed by parents who fear that imparting sex education would lead to experimentation with sex.

The above studies reflect the Attitude of Parents towards Sex Education. However, the studies result in a low or a moderate attitude towards sex education. This kind of attitude has prevailed for decades in the Indian society. Parents find it unnecessary for their children to learn or know more about sexual intercourse and reproduction. It is still considered to be a taboo from the society's point of view. However, they overlook the fact that it is very important for the young adolescents to know about the various changes that take place as it is in their teenage that they are more inclined towards sexual activities. Teenage is a crucial phase of life. Lack of sufficient knowledge could lead to unwanted pregnancies, abortions and STD's. Teenagers who find it difficult to discuss upon such topics with their parents make use of sources such as movies, internet, books etc. to know more about it. These sources may not give a clear idea and the teenagers may receive improper knowledge on the topic which may lead to emotional disturbances. Hence, it is better if they receive proper information through formal Sex Education programs in schools, colleges and proper guidance from parents or significant others. The existence of AIDS has given a new sense of urgency to the topic of Sex Education. Since the policies recommending Sex Education have been opposed by a majority of parents earlier, especially in the developing countries, it is important to have some epidemiological data pertaining to the attitudes of parents towards Sex Education to show the shift of their attitudes from negative to positive. The present study is a modest attempt to explore the attitude of parents of today's teenagers.

\section{AIMS AND OBJECTIVES :}

1. To study the attitude of parents of teenagers towards Sex Education.

2. To identify whether there is any difference in the attitude of mothers and fathers.

\section{HYPOTHESES :}

1. The attitude of parents of teenagers (13-19 years) is high towards Sex Education.

2. There may be a difference between the attitude of mothers and fathers.

\section{METHODOLOGY}

- Research Design: The present study adopts descriptive research design which involves collecting data and testing hypothesis concerning to the current status of the subject of study. In the present study, information is gathered regarding the existing attitude of parents towards Sex Education.

- Sample: The sample consisted of 60 parents whose children fall in the age group of 13-19 years. The study was conducted in a metropolitan city of India. 30 mothers and 30 fathers of teenagers were taken to study their attitude towards Sex Education. For this research, 
purposive sampling technique which comes under the broader section of Non Probability sampling method was used.

- Tools: The questionnaire on Attitude Scale towards Sex Education developed by Dr. Usha Mishra (2008) was used. The scale consists of 32 items in which 16 items are of positive attitude and 16 items are of negative attitude. The scale used is standardized and has been checked on its reliability which was computed by Spearman Brown Prophecy formula and the value found is 0.86 . The items on the scale have been critically examined by 25 experts and their opinion confirmed that it has context and face validity.

- Data analysis: For analyzing the data, the descriptive statistics; percentage and means and the inferential statistics; t-ratio was used.

\section{RESULTS}

- Table 1 represents the attitude of parents towards Sex Education in percentage.

\begin{tabular}{|l|l|}
\hline Interpretation & Percentage \\
\hline Very high & $38.33 \%$ \\
\hline High & $53.33 \%$ \\
\hline Moderate & $8.33 \%$ \\
\hline Low & - \\
\hline Very low & - \\
\hline
\end{tabular}

- Figure 1 represents the attitude of parents towards Sex Education in the form of a pie diagram.

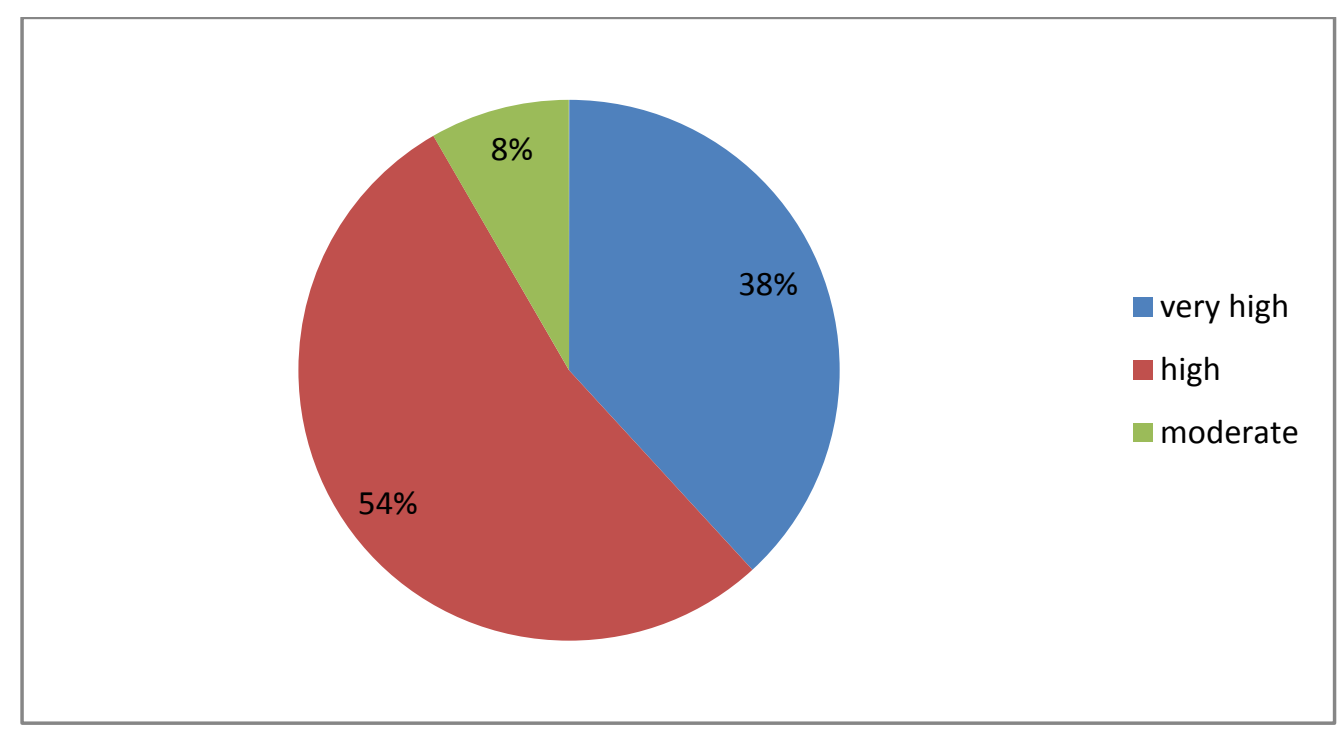


- Table 2 indicating the means and the t-ratio.

\begin{tabular}{|l|l|l|l|l|}
\hline Number -30 & Fathers & Mothers & t-ratio & p value \\
\hline Mean & 117.16 & 115.63 & \multirow{2}{*}{0.448} & $<0.05$ \\
\hline S.D & 12.20 & 13.73 & & \\
\hline
\end{tabular}

- Figure 2 represents the means of fathers and mothers in the form of a bar diagram.

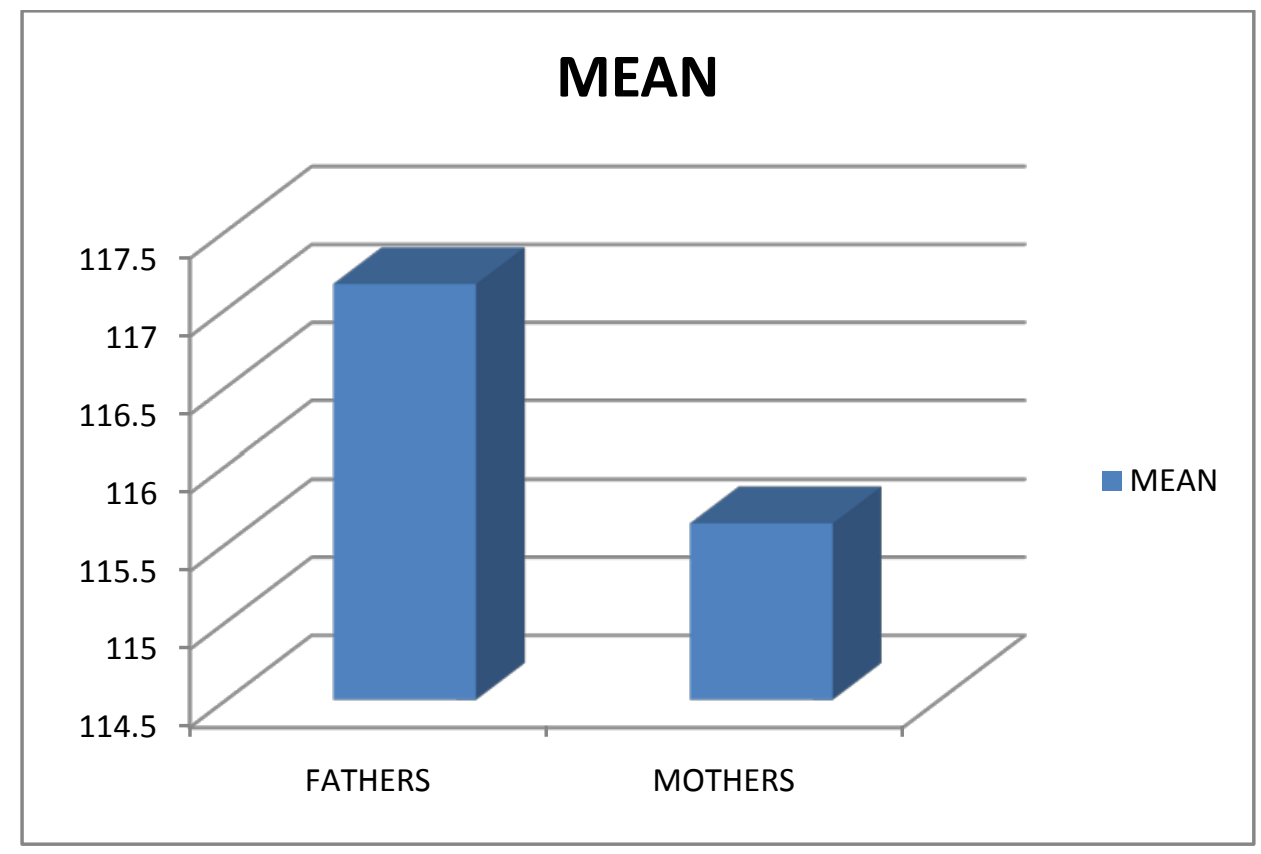

\section{DISCUSSION}

The findings from the study show that the attitude of parents of teenagers is positive towards Sex Education. 38.33\% of the sample has a very high attitude, 53.33\% records for a high attitude and the rest $8.33 \%$ for moderate attitude as indicated in table 1 . None of the participants fall under the low or the very low attitude category thus supporting the first hypothesis that attitude of parents of teenagers is positive towards Sex Education.

When the mothers and fathers scores are compared, the fathers' attitude is noted to be slightly higher than that of the mothers. Fathers mean being 117.16 and mothers mean being 115.63 and the mean difference being 1.53 indicates that there is no significant gender variation although both the genders have a significantly high attitude towards Sex Education. The t-ratio being 0.448 is not significant. Though the difference is minimal, it still supports that fathers have a high attitude than mothers but it is not statistically significant. 
The present study comes with a proposal stating that more studies could be done on a wider level using Probability Sampling technique to strengthen the findings of the present study and to support the change in the attitude of parents towards Sex Education. Such findings can motivate the governmental and non governmental agencies working towards the institutionalization of Sex Education, to come up with long lasting policies and awareness campaigns.

\section{SUMMARY AND CONCLUSION}

The results of the present study show that the parents of today's teenagers have a high attitude towards Sex Education with no significant gender variation. This shows that parents have become more open to issues like Sex Education and its various aspects. More studies could be done in this area to support the findings of the present study.

\section{REFERENCES}

Borland, S. (2007, December). Sex Education 'leaves teenagers clueless’. Frost's Meditations.

Dialard, C. (2001, February). The Guttmacher Report on Public Policy, 4(1).

Hovell, M. (1994, November). Journal of Marriage and Family, 56(4).

Libby, R.W. (1970). Parental Attitudes toward High School Sex Education Programs. The Family Coordinator, 19(3) 234.

Mahajan, P., Sharma, N. (2005). Parents Attitude towards Imparting Sex Education to their Adolescent Girls. Anthropologist, 7(3) 197-199.

Oiekh, A.J. (1981). The Place of Sex Education in Secondary Schools in Nigeria. Nigeria School Health Journal, 3(1).

Shetty, P., Patil, V., Kowli, S. (1999). Attitude of Mothers towards Sex Education of Adolescent Girls. Regional Health Forum, WHO IRIS. 